\title{
Weight Gain Due to Fluid Retention
}

National Cancer Institute

\section{Source}

National Cancer Institute. Weight Gain Due to Fluid Retention. NCI Thesaurus. Code

C119200.

A finding of rapid weight gain due to fluid retention. 